\title{
Towards breaking the gender gap in Science, Technology, Engineering and Mathematics
}

\author{
Emilia López-Iñesta, Carmen Botella, Senior Member, IEEE, Silvia Rueda, Anabel Forte and Paula Marzal
}

\begin{abstract}
NOTICE: this is the authors' version of a work that was accepted for publication in The IEEE Journal of Latin-American Learning Technologies (IEEE-RITA). Changes resulting from the publishing process, such as peer review, editing, corrections, structural formatting, and other quality control mechanisms may not be reflected in this document. Changes may have been made to this work since it was submitted for publication.

A definitive version was subsequently published in The IEEE Journal of Latin-American Learning Technologies (IEEE-RITA), Available Online on 09 July 2020, DOI:https://doi.org/10.1109/RITA.2020. 3008114, https://ieeexplore.ieee.org/document/9137264

Abstract-The gender gap in Science, Technology, Engineering and Mathematics (STEM) has drawn the attention of research and academic communities due to its impact in the Digital Society, targeting the fourth and fifth 2030 sustainable development goals of achieving quality education and gender equality. Recent studies show that women are enrolling STEM studies in smaller proportion than men and that they have a larger probability to renounce to their jobs or to take leaves. In this scenario, the involvement of educational institutions is seminal to change this trend. The School of Engineering of the University of Valencia (ETSE-UV), Spain, launched in 2011 a pilot program to promote STEM careers, focusing on increasing and retaining the number of female students choosing these studies. Building from this experience, the Girls4STEM project has been launched in 2019 with the aim of reaching female students from 6 to 18 years old, their families and teachers. In this paper, we present and motivate the project's objectives and main activities, framing them in current state of the art's literature. Preliminary results of the pilot program actions are presented, demonstrating the statistically significant impact on the percentage of enrolled female students and motivating the subsequent Girls4STEM project.
\end{abstract}

Index Terms-Gender gap, STEM, ICT , Girls4STEM

\section{INTRODUCTION}

$\mathbf{S}^{\mathrm{E}}$ EVERAL analysis and studies have proved that the number of women entering Science, Technology, Engineering and Mathematics (STEM) academic degrees has been decreasing over the last twenty years, with an uneven distribution among the different STEM branches and a larger impact in the Information and Communications Technology (ICT) field [1]. Currently, there is already a shortage of STEM talent, in areas with a broad range of job positions and good working conditions. At the same time, technology forecasting predicts that big data, artificial intelligence and advanced communications systems such as 5G-NR and beyond 5G will increase the demand for STEM talent and of ICT in particular, driving us towards a Digital

E. López-Iñesta is with the Departament de Didàctica de la Matemàtica, Facultat de Magisteri, University of Valencia, Spain.

C. Botella and S. Rueda are with the Departament d'Informàtica, ETSE-UV, University of Valencia, Spain.

A. Forte is with the Departament d'Estadística i Investigació Operativa, Facultat de Matemátiques, University of valencia, Spain.

P. Marzal is with the Departament d'Enginyeria Química, ETSE-UV, University of Valencia, Spain.
Society with a profound transformation of the job market. In this context, the potential of half of the population cannot be ignored. Thus, it is mandatory that women (an other minorities) become an active part in the definition of the future society as it is considered in the 2030 Sustainable Development Agenda with the aim of promoting women's empowerment, mainstream gender equality and ensure a quality education, objectives specifically fixed in the fourth and fifth Sustainable Development Goals ${ }^{1}$ (SDG4 and SDG5), which explicitly refer to the ICT field as an enabler to promote the empowerment of women.

Despite all these efforts, women already working in STEM sectors show a larger probability of moving to other professional sectors, requesting a leave of absence or working part-time, especially at the stage of upbringing their children and/or taking care of elders [2]. In fact, studies show that women graduating in STEM fields do not always access to STEM occupations, appearing a phenomenon known as the 'leaking pipeline' [3]. As a combination of these factors, women face barriers and challenges in their professional careers both in industry and academia that worsens their STEM percentage [4][6], regardless of all the evidence supporting the need for diverse teams in terms of creativity or work fulfillment, for example [7]. Although work-life conflicts have been pointed out for a long time as a key factor to resolve in STEM careers, due to a high professional demand and the disciplines fast change, people accessing to flexibility measures can be penalized by what is known as the 'flexibilization stigma' [4]. Interestingly, a recent study performed over the Spanish market [8] proved that flexible work measures do not seem to be the solution for the particular case of the ICT sector, since the weight of factors such as stereotypes related to gender or age, lack of leading roles, or male-dominated and aggressive self-confidence working environments was much higher.

Based on the above, the shortage of female STEM vocations can be tackled from three perspectives: i) increasing the number of female students in STEM academic degrees, ii) retaining and engaging them once they have entered the studies and iii) building support networks at the professional level. In this paper, we elaborate around the first part of the problem, i.e., how can we deal with the shortage of female STEM vocations. In particular, we introduce the Girls4STEM project, an initiative launched in 2019 at the University of Valencia (Spain), aligned with the measures proposed in its III Plan of Equality. This project is an extension of a pilot program developed since 2011 at the School of Engineering of the University of Valencia (ETSEUV), which has helped to increase the percentage of female students registered in Computer Science Engineering related degrees seven points above the Spanish national average [9]. Girls4STEM is an umbrella project that encompasses all the ETSE-UV's activities and action lines towards decreasing the gender gap in STEM disciplines. This project is supported and participated by several institutions, companies and regional actors, but its main value arises from the interaction between pre-university students and STEM experts, which constitutes an intervention tactic that helps visualizing the societal impact of STEM. As we will motivate, the participation of higher education institutions is seminal to engage and attract girls into STEM areas.

In this context, we consider two research hypotheses:

${ }^{1}$ https://en.unesco.org/sdgs 
- H1: The pilot program's effect has been larger in STEM fields with larger gender gap.

- H2: A continuous effort is needed in all STEM fields, even in traditionally gender balanced STEM studies.

This paper expands the work presented in [10], where actions and motivation of the pilot program were presented. The main contributions of this paper are the following:

- The need for female STEM vocations and professionals, specially for the ICT sector, is motivated.

- Evidence is given to challenge the common thought that states that girls do not access STEM disciplines because 'they do not like them'.

- Lines of action (study plans, research, dissemination and operating schemes) for promoting STEM vocations from a higher education institution perspective are discussed.

- The Girls4STEM project is presented and previous pilot program results achieved at the ETSE-UV are analyzed. These outcomes will reflect the need for a continuous effort in this direction, since, as it will be shown, even traditionally femaledominated degrees can suffer the leakage of vocations to other areas.

In the next Section, we will consider the impact of the gender gap in STEM and ICT, and the freedom of choice assumption will be challenged. Section III reviews the ETSE-UV's background and action lines in the 2011-2018 window, and motivates the need for further efforts. Section IV presents the Girls4STEM project, describing its objectives and activities. Preliminary results are given in Section V, and conclusions are drawn in Section VI.

\section{WOMEN ARE NOT A MAJORITY IN THE ICT AREAS, BUT SHOULD WE REALLY CARE?}

The Fourth Industrial Revolution characterized by technological advancement is set to create entirely new opportunities in the STEM labour market [11]. In fact, the growth in employment in STEMrelated occupations where technology skills are essential (e.g. Computer Science, Information Systems and Engineering) is projected to rise by $13 \%$ for the period 2015-2025 according to the European Commission [12], while it has been estimated a $3 \%$ for the rest of job positions in the same period. As stated in Section I, in spite of the growing demand of technological and digital profiles, there is a decreasing common trend both for men and women to be enrolled in ICT-related degrees or associated technical vocational education and training programs, but figures indicate that there are less women than men [13].

As a result, nowadays there is a great challenge to prepare the future workforce that is intimately related to narrowing the gender gap in STEM and ICT studies around the world. But to achieve a real progress, it is important for the whole society to be aware of how significant is the transformative impact of ICT and what implications has the low presence of women in a technology sector that often forgets to include a gender perspective in its projects. This omission may have critical consequences in discrimination against women or other minority groups in, for example, the design of machine learning algorithms that are used as assistants for decision making in many situations of our daily life, such as hiring a health insurance and its coverage, management of admissions in schools or universities, loan applications approval or finding a job [14], [15]. However, despite the efforts made by regional, national and international initiatives such as STEM Talent Girl ${ }^{2}$, Women Techmakers ${ }^{3}$ or the project named '¿Por qué tan pocas?' that try to reduce the gender gap in technology fields and promote scientific vocations among students from different educational levels, organizations such as UNESCO have determined that worldwide women represent $35 \%$ of students

\footnotetext{
${ }^{2}$ https://talent-girl.com/

${ }^{3}$ https://www.womentechmakers.com/

${ }^{4} \mathrm{https}: / /$ porquetanpocas.com/
}

in STEM disciplines, with percentages that fall to $3 \%$ in the ICT sector.

If we focus on the situation in Spain and on the specific case of careers related to Computing, the proportion of registered women has decreased from 30\% (academic year 1985-1986) to less than 13\% (academic year 2017-2018) [16]. In fact, focusing on the last 7 years, it has gone from 13,36\% in the 2010-2011 academic year to $12,06 \%$ in the $2016-2017$ academic year. However, the female presence in STEM studies such as Medicine, Biological Sciences or Pharmacy has increased significantly [17], producing a non-uniform distribution among study areas [1], [18]. Specifically, the branch of Health Sciences shows an increase of around $10 \%$ of women enrolled since 1987 , maintaining its proportion around the $70 \%$ in a sustained way over the last years. These data would give support to the current of thought that establishes and tries to demonstrate that women are present in Science in general, and that if they do not opt for the STEM disciplines and especially ICT, it is because they do not like them, taking for established and sure the freedom of choice, but, is this freedom of choice real and not conditioned to the environment?

\section{A. The freedom of choice}

Authors such as Eccles and Wigfield [19] explain from Psychology theory and through the expectancy-value model of choice linked to achievement, that individual's educational and occupational decisions are motivated by a combination of two factors: people's expectations for success and subjective task value (in terms of interest-enjoyment value, cost and utility value). These two components are interrelated: people only enroll in those studies that they consider they can overcome because they possess the necessary skills to develop them. Besides that, people choose studies that represent an important value for them and meet their expectations of success.

Nevertheless, these are not free decisions since both the expectations of success and the perceived value are conditioned to gender roles and to the influence of the school, family and community environment in which we find ourselves [20]. Thus, as Sáinz [21] pointed out, the authors in [20] explain why girls prefer to dedicate themselves professionally to careers that have a priori a greater social impact linked to people care development and interpersonal relationships, and do not opt for careers like Engineering, traditionally considered as 'eminently masculine' These arguments are in line with Weisgram and Bigler studies [22] that confirm that values such as altruism affect career decisions, showing that women are more likely than men to value helping others in their work.

Documents such as [23] establish that the fundamental stage that influences these decisions is located between 6 and 15 years. Starting from the proven base that both boys and girls do not show any difference in terms of mathematical reasoning [24], we see that there are a series of family and social factors that support the creation of gender or sex roles, as well as stereotypes which interfere and have an impact on the choice of future studies of children [22]. If we go to the professional stage, the surveys that have been conducted among women state that the main barriers they encounter are the lack of mentors in the professional stage/period/phase, the lack of reference models, the existence of gender biases in the workplace, the lack of equal opportunities or the fact of receiving a lower salary for the same professional category [4]. These professionals also find, that the main reasons why women do not choose STEM disciplines are due to gender and sex roles, the fact that they are male dominated professions, the lack of balance between professional and personal life, and the lack of support from educational institutions [4].

\section{PROMOTING GENDER DIVERSITY FROM A HIGHER EDUCATION INSTITUTION}

From our perspective, women cannot be forgotten in the future Digital Society, they must actively contribute to its definition and construction. The slow progress towards narrowing the gender gap requires a new perspective on the subject. To promote STEM 
vocations among youth, especially among girls, the participation of educational institutions is a key factor. Since the critical age range is located in the pre-university stage, it is possible that higher education institutions consider that they are not part of the solution to the problem. However, we advocate that Universities, Faculties, and especially Engineering Schools should take a step forward and incorporate the gender perspective in three fundamental lines. i.e., study plans, research and dissemination activities, as well as in their operating scheme.

Several attempts have been made to incorporate gender perspective in the higher education curriculum. One example of a good practice consists in the introduction of gender perspective in the teaching of software Engineering at University of Salamanca (Spain) [25]. Authors present an innovative educational experience where students show that they were not aware of the gender gap beyond the low number of women enrolled in Computer Science Engineering degrees. Another interesting initiative is the one by the Vives Network ${ }^{5}$, a non-profit institution that coordinates joint actions of 22 Universities in 4 European states. This network has published a collection of 11 Guides for University teaching to include gender perspective in resources in teaching, research and management ${ }^{6}$.

Including the gender/sex analysis into research has been referred to as 'gendered innovation', an initiative led by Professor Londa Schiebinger (http://genderedinnovations.stanford.edu), which justifies the inclusion of the gender perspective into research due to the benefits in many fields, ranging from medicine to engineering and technology [26]. Both the European Commission and the US National Science Foundation have funded projects working on this item, identified by the European Union as one of the Responsible Research and Innovation (RRI) indicators in Science and Technology. Examples of these projects are for example the European COST action GenderSTE (Gender, Science, Technology and Environment, https://www. gendersteunescochair.com/project/genderste/), or the H2020 project GEECCO (Gender Equality in Engineering through Communication and Commitment, http://www.geecco-project.eu).

In addition, higher education institutions play a significant role to carry out a dissemination of the social applicability of STEM, highlighting the final link between the disciplines and society. In this way, higher education institutions can act in three dimensions: i) interacting with families, primary and secondary education centers and other agents to promote inclusive and equitable quality teachinglearning processes from childhood, ii) collaborating with alumnae graduates to build professional support networks; and iii) supporting students who have already completed the studies [10]. These actions promote lifelong learning opportunities for all, an aspect included in the SDG4 to obtain a quality education. In this sense, it is especially important to try to reach the age range between 6 and 15 years, where one of the most immediate options is to raise outreach activities that increase the visibility of women who work in STEM areas, since, as it is indicated by UNESCO [1], it is essential that girls see female role models to identify themselves, so that they can 'imagine' themselves developing those roles, as well as understanding that women are also referents in these fields. In fact, there are outreach programmes analyzing the influence on the attitude towards Science in terms of age and focusing on girls, such as those developed in Spain [27], [28] and other countries as for example [29]. Likewise, these outreach activities should ensure the active participation of important agents such as families, teachers, professional entities and companies in order to give visibility to the scientific advances of the STEM disciplines and connect them to society. Interestingly, out-of-school time STEM activities and informal learning environments (campuses, camps, etc.) have been shown to be important factors that can make a difference to increase student's interest in STEM disciplines [30][33], increasing up to 1,8 times the chances of a student to enroll in a STEM degree. However, other research indicates that, despite the innumerable initiatives and efforts, outreach activities have a much

\footnotetext{
${ }^{5}$ https://www.vives.org/

${ }^{6} \mathrm{https}: / /$ www.vives.org/programes/igualtat-genere/
}

smaller impact on girls, especially in the field of Engineering [34], [35].

Finally, higher education institutions should adopt gender equality plans, addressing the issues of increasing the visibility of female researchers and teachers, promoting equal parenting, establishing flexible work arrangements and preventing the gender wage gap. Equality plans need to focus on the long-term, avoiding simple criterion such as increasing the number of women. Instead, including the consideration of merits and qualifications and building a welcoming and supporting working environment for women are preferable, since the stigma of incompetence can be inferred to women accessing affirmative actions [36].

\section{A. ETSE-UV: Closing the gender gap since 2011}

The ETSE-UV, through its role as a higher education institution covering undergraduate, master and $\mathrm{PhD}$ levels, can tackle the gender gap problem mainly from two directions. First, promoting the interaction with secondary schools (fighting stereotypes via establishing female role models) and second, retaining and engaging female students accessing the studies. One seminal component of the ETSEUV's pilot program is the transmission of the opportunity offered by STEM disciplines for achieving a communal goal. In fact, we believe that highlighting the final link to people is fundamental to engage female students [22], [37].

The program developed by the ETSE-UV since 2011 is aligned with some of the directions proposed in [1], such as the extracurricular student engagement, the mentorship, and female role models. As this report points out, promoting more female role models in STEM fields (increasing the number of female students and faculty members in higher education), is mandatory to attract women and girls to STEM fields. Therefore, four main actions have been implemented at the ETSE-UV: i) Providing institutional encouragement and support for the students; ii) increasing the professional support network after graduation; iii) promoting and supporting the leadership for faculty staff; and iv) increasing the visibility of female role models. These four actions have been developed through the implementation of several activities, both taking place at the ETSEUV facilities and outside the School. A description of the activities, their link to the literature of the topic, as well as references to parallel initiatives and an exploratory analysis of the results (detailed for each one of the offered degrees) can be found at [10]. This preliminary assessment confirms that the ETSE-UV's pilot program is contributing in part to reduce the School's gender gap. However, in 2019, the Girls4STEM project has been launched as an umbrella covering and extending the current working program. Basically, the need to reach younger girls (under 15) and to reinforce the interaction with the ecosystem surrounding them (families, school, friends) was put forward. In the next Section, the aim and main guidelines of this project will be stated.

\section{GIRLS4STEM: OBJECTIVES AND MOTIVATION}

As it has been discussed in Section III, one strategy to increase the student's interest in STEM is to create informal learning environments. However, evidence also indicates that outreach activities have a lower impact on girls unless they open the possibility for the girls to visualize themselves in the role. Recently, reference [38] has proposed a framework to classify social psychological theories focusing on the incongruities that contribute to the gender gap in STEM: dissociation between STEM contexts and women, and the lower expectancy-value theories. The authors extract a common ground model with three main strategies (to challenge stereotypes, to align with values and to promote growth of attitudes) and identify two intervention tactics, including the arrangement of activities with speakers from a broad range of identities, to highlight the societal impact of their work. This intervention tactic is the Girls4STEM's cornerstone activity. The project has been conceived as an extension of the ETSE-UV's pilot program [10], covering and extending the activities that started in 2011 and that have been detailed in [9]. Basically, the main 
difference is the extension of the targeted audience by covering a broader range of pre-university ages (from 6 to 18 years old), as well as their environment (family, teachers/professors). The project is supported by many actors (public institutions, regional entities, companies and professional entities) and it builds from the interaction between female STEM experts and the participating students.

The specific objectives are defined as follows:

1) Promote STEM vocations;

2) Seek the active participation of several actors: students, families, teachers, professional entities and companies;

3) Increase the visibility of scientific STEM advances and connect them to their societal value;

4) Increase the visibility of female STEM researchers and professionals' contributions.

These specific objectives will be tackled by arranging a set of public events where several 'public speeches' will be given by the female STEM researchers or professionals participating in the project (note that regaining the presence of women in 'public speech' events, as for example in plenary sessions of academic conferences, has been also an intervention tactic sought or discussed by many authors [39], [40]).

Two main kind of events are planned, differentiated according to the targeted audience. On the one hand, there will be a set of sessions for the pre-university students and their families ('Girls4STEM Family'). Before these sessions, students and their teachers should choose one female STEM expert based on a short biography available on the project website (these experts are collaborators of the project). The request is made through a form prepared on the website and once the experts have been assigned to the schools, the students interact with the expert in several possible ways: by visiting her workplace, through a videoconference or meeting the expert in their school or high school. The students should take notes and prepare material for a three minutes video long and when possible, for the realization of a Wikipedia page about the expert in order to give visibility to her work. The objective is to provide real contact with a female STEM referent and allow students to prepare questions about her professional career, the reasons that led her to choose a degree in the STEM field, the advantages and possibilities of a career in this area, the obstacles she faced, etc. All this work will be exhibited in a 'family' session where students and teachers from different centers and their families will enjoy a morning session in a leisure environment sharing knowledge about the STEM area. First, the students will describe the interaction with the STEM expert, with the aim of discovering her daily work and achievements, and they will play the video showing their selected STEM expert day-today work and share (if possible) the Wikipedia page of the STEM expert. The STEM expert will give a public talk after that. Note that the participating schools will obtain material such as tablets or 3D-printers in acknowledgement for their participation. On the other hand, the second set of sessions ('Girls4STEM Professional') targets an adult audience, mainly professionals and teachers. In this case, a group of 4 female STEM experts will give a talk with the aim of including the gender perspective into the research and professional environments, rising awareness of the gender gap. Since the talks are given out of school hours, the teachers attending these sessions (Family or Professional) will be given a certificate by the Educational regional entity participating in the project.

All the information regarding the STEM experts, the participating schools, the videos, the biographies and the conferences will be published via the project's website ${ }^{7}$ and the social media profiles in Facebook ${ }^{8}$, Twitter ${ }^{9}$ and Instagram ${ }^{10}$. Note that these activities will run in parallel with the current working program [10].

\footnotetext{
${ }^{7}$ https://girls4stem.es

${ }^{8}$ https://www.facebook.com/Girsl4STEM

${ }^{9}$ https://www.twitter.com/Girls4STEMVLC

${ }^{10} \mathrm{https} / / / \mathrm{www}$. instagram.com/girls4stemvlc
}

\section{A. Evaluating the project}

Evaluating gender-based intervention initiatives is not straightforward (see discussion in [10]). The Girls4STEM project is one-group action, so it will not be possible to establish a control group. Due to this, it is necessary to design appropriate tools and methods to provide the evidence needed to asses the success and performance of the project. The work carried out in [34] will be taken as a reference. According to this document, 'public speech' sessions have a positive impact over three dimensions: i) it increases the self-efficacy by means of the interaction with STEM professionals (promoting STEM vocations); ii) it presents STEM disciplines as a valid tool to achieve a communal goal, allowing to give visibility to STEM role models (increasing the impact over students who were not believing STEM to be an option for them); and iii) it helps to include information for professional orientation.

The project will evaluate both the quantitative and qualitative dimensions. The quantitative dimension is given by the potential audience of each public event (around 100 people). Tests of questions will be collected in both set of sessions, differentiating between students and adults (teachers, families, professionals). One instrument that has been previously validated on the field of gender education and ICT-related subjects is the GENCE questionnaire about the inclusion of the GENder perspective in Computer Engineering [41], that was designed to ask undergraduate students about their knowledge and opinion on gender issues in their studies/career. Therefore, we will take as a basis both [34] and the GENCE questionnaire [41] to obtain a useful element for assessment of the action. In addition, since actions out of school time are mainly followed by motivated families, questions will be added to identify the success of the project with respect to a priori non-motivated families.

To perform the tests, online tools such as Kahoot ${ }^{11}$ or Socrative ${ }^{12}$ will be used. These tools have encouraged the development of new participatory strategies based on the use of digital devices. In fact, these applications can be used as audience response tools or electronic voting systems, but also allow us to design games and organize challenges. The introduction of gamification elements using these tools can bring many benefits from the motivational, engagement and participation point of view both for adults and students [42], [43]. The aim of using these online audience response tools is twofold: on the one hand, the use of a gamification tool for the design of questionnaires that allow us to interact with the students, families and attendees; on the other hand, to obtain data on student's knowledge before and after receiving information and instruction about the Girls4STEM project. A pre- and post-test will be conducted in each group in order to measure the parameters stated above. Data analysis tools will be used to evaluate this input, targeting a longitudinal analysis in the long round for an effective assessment. In addition, big data tools to effectively visualize and treat the data will be used to assess the impact of the project in social networks (use of the hashtag \#Girls4STEM will be encouraged, so a potential analysis of the gathered data can be performed) [44].

In the next Section, we present an analysis of the ETSE-UV's current results in the number of enrolled undergraduate female STEM students in three STEM disciplines, and based on its outcomes, motivate the need for a continuous effort towards decreasing the gender gap.

\section{PREliminary RESUlts}

The ETSE-UV offers the Engineering studies of the University of Valencia, that is, Chemical Engineering, Computer Science Engineering, Industrial Electronic Engineering, Multimedia Engineering, Telecommunications Electronic Engineering, Telematics Engineering, and Data Science. The School offer is focused on Engineering studies, but the degrees cover several core STEM subjects (Chemistry, Mathematics, Physics, Informatics, Electronic Engineering and

\footnotetext{
${ }^{11}$ https://kahoot.it

${ }^{12} \mathrm{https} / / /$ socrative.com/
} 


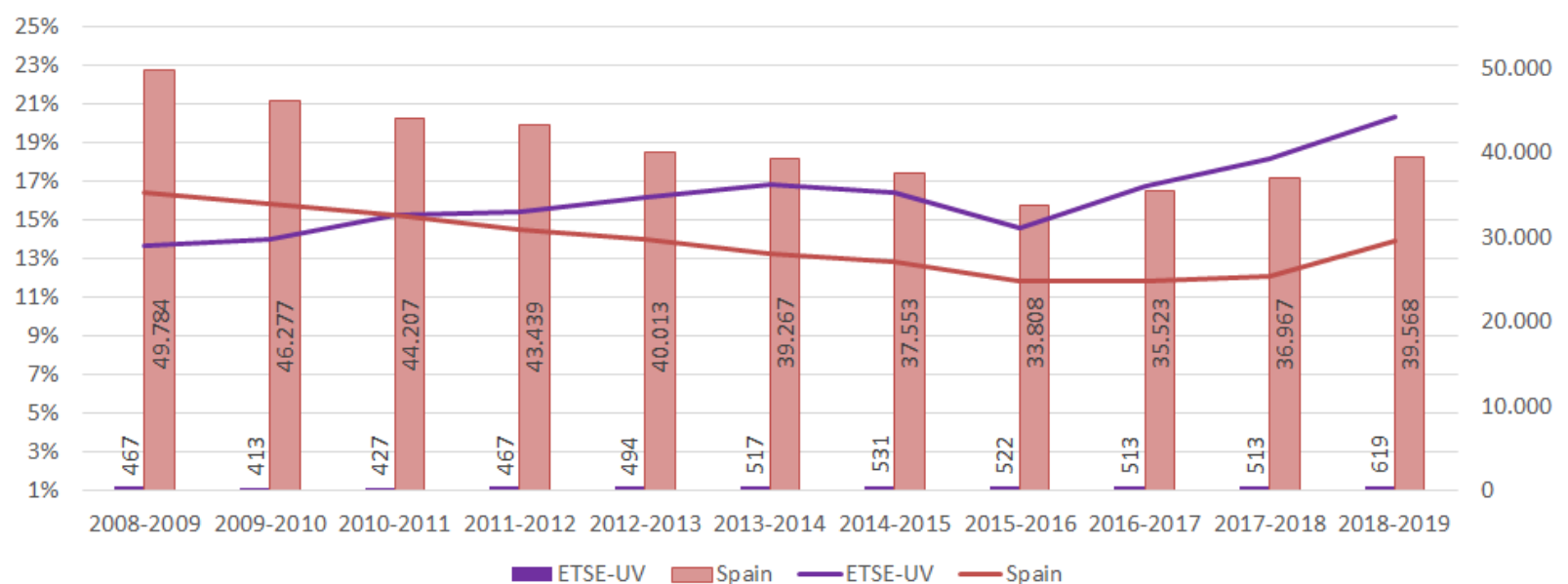

Fig. 1. Percentage of female students at the ETSE-UV vs. total number of students (undergraduate). Spain's situation is used as a benchmark. Aggregated data of fields '06 - Informatics' and '071401 - Computer Engineering'.

TABLE I

VARIABLES FOR DATA SELECTION

\begin{tabular}{|l|l|}
\hline Degrees & ISCED-F 2013 fields \\
\hline \hline Comp. Science Eng. & 06 - Informatics \\
Multimedia Eng. & 071401 - Computer Eng. \\
\hline Telematics Eng. & 071405 - Electronic Eng. \\
Tel. Electronic Eng. & \\
\hline Chemical Eng. & 071101 - Industrial Chemical Eng. \\
\hline
\end{tabular}

Telecommunication) and hence, narrowing the gender gap in this scenario becomes a larger challenge. It has to be noted that, except Multimedia Engineering and Telematics Engineering, the remaining degrees are also offered by specialized Faculties at the Technical University of Valencia, located in the same city, and thus, a substantial effort needs to be done to attract students.

In this Section we present results from the ETSE-UV's pilot program starting in 2011. More precisely, we will process data related to ICT degrees, and consider the special case of Chemical Engineering to illustrate the need for further efforts, covering also STEM subjects that have traditionally been assumed to be gender balanced. To evaluate the impact of the program, we use the data available in [16]. Following the Ministry classification, the ETSE-UV's data for Computer Science Engineering and Multimedia Engineering has been aggregated, as well as for Telematics Engineering and Telecommunications Electronic Engineering. For the sake of reproducible research, Table I indicates the fields that have been selected in [16] to obtain the data for each considered degree. Note that data in [16] has been divided in two time periods (before and after 2015), and due to this, Spain's aggregated data shows some discontinuity related to the transient between Pre and Bologna-compliant degrees. In addition, the International Standard Classification of Education (ISCED-F) has been used by the Ministry to arrange the data. Options 'Universidad Pública Presencial' (Public on-site University) and 'centros propios' (own premises) need also to be selected. In our case, we use Spain's data (available in July 2019) as a benchmark in each one of these fields.

Evaluation of the pilot program is not straightforward, since all the actions and activities have been carried out over the whole community, i.e., there is no control group. However, we use as a reference the analysis from [45], where one of the key points is to evaluate the percentage of registered female students. In addition, it has to be noted that in 2010 the Bologna-compliant degrees started at Spain (in general). Therefore, there is a transient window between
2010-2011 and 2013-2014 where both Pre and Bologna-compliant degrees were coexisting.

Fig. 1 shows the evolution in the percentage of female students both at the ETSE-UV and Spain (lines, left axis) and in the total number of students (bars, right axis) for the aggregated fields '06 Informatics' and '071401 - Computer Engineering'. In the ETSEUV's case, data is aggregated for Computer Science Engineering (Pre-Bologna, 5 years), Computer Science Engineering, Multimedia Engineering and Data Science (Bologna-compliant, 4 years). Note that Data Science is a degree that started in 2018-2019. Results show that the percentage of female students at the ETSE-UV was below the Spain's average at the beginning of the period. However, it has been steadily increasing until a difference of almost $7 \%$ in average $(13,80 \%$ Spain, $20,36 \%$ ETSE-UV) has been reached.

Fig. 2 depicts the results regarding the percentage of female students both at the ETSE-UV and Spain (lines, left axis) and in the total number of students (bars, right axis) for the field '071405 Electronic Engineering'. In the ETSE-UV's case, data is aggregated for Telematics Engineering, Telecommunications Electronic Engineering (Pre-Bologna, 3 years), Electronic Engineering (Pre-Bologna, 5 years), Telematics Engineering and Telecommunications Electronic Engineering (Bologna-compliant, 4 years). In this case, the ETSEUV's percentage remains below the Spain's average for the whole period under consideration, although a positive trend can be observed, remaining around a $1 \%$ from each other at the end of the period (16,61\% Spain, $15,30 \%$ ETSE-UV).

The pilot program developed from 2011 directed a stronger effort towards the ICT degrees offered by the School, since, traditionally, Chemical Engineering has been a more gender balanced degree. However, data analysis reflects a negative trend in this degree, highlighting the need for a continuous effort towards decreasing the gender gap in all STEM related degrees, even the ones that have been usually more female-dominated. Fig. 3 illustrates the percentage of female students both at the ETSE-UV and Spain (lines, left axis) and in the total number of students (bars, right, axis) for the field '071101 - Industrial Chemical Engineering'. As it can be seen from the Figure, the percentage of female students is steadily decreasing in Spain, starting from a $52,42 \%$ in the academic year 2008-2009 and reaching a 43,05\% in 2018-2019. In the ETSE-UV's case, although the percentage remains over the Spanish baseline, results also show a negative trend (from a maximum of $55,52 \%$ to a minimum of $45 \%$ in the period under consideration), evidencing the need for active gender-based policies in this STEM branch.

In the following, a logistic regression model has been considered in order to test whether the program had an effect (at 0,05 significance level) in the proportion of registered female students at the ETSEUV. Note that in this study, the available data has been divided in a 


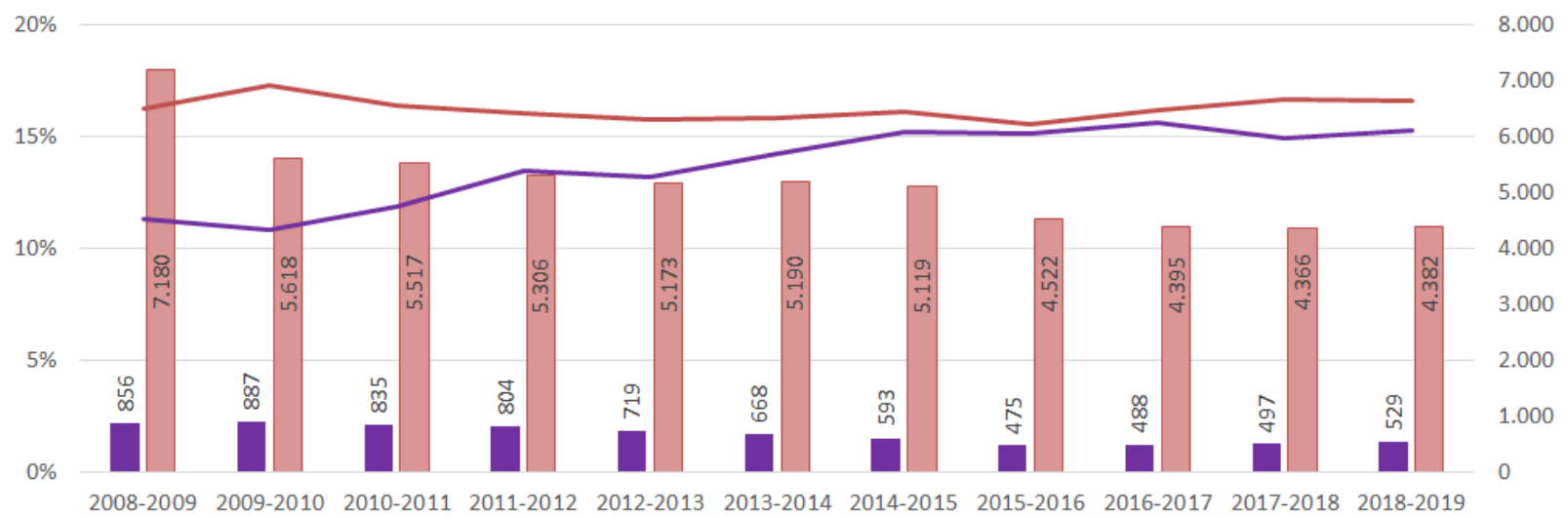

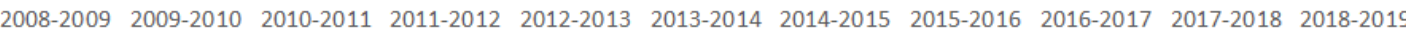

ETSE-UV $\square$ Spain —ETSE-UV —Spain

Fig. 2. Percentage of female students at the ETSE-UV vs. total number of students (undergraduate). Spain's situation is used as a benchmark. Field '071405 - Electronic Engineering'.

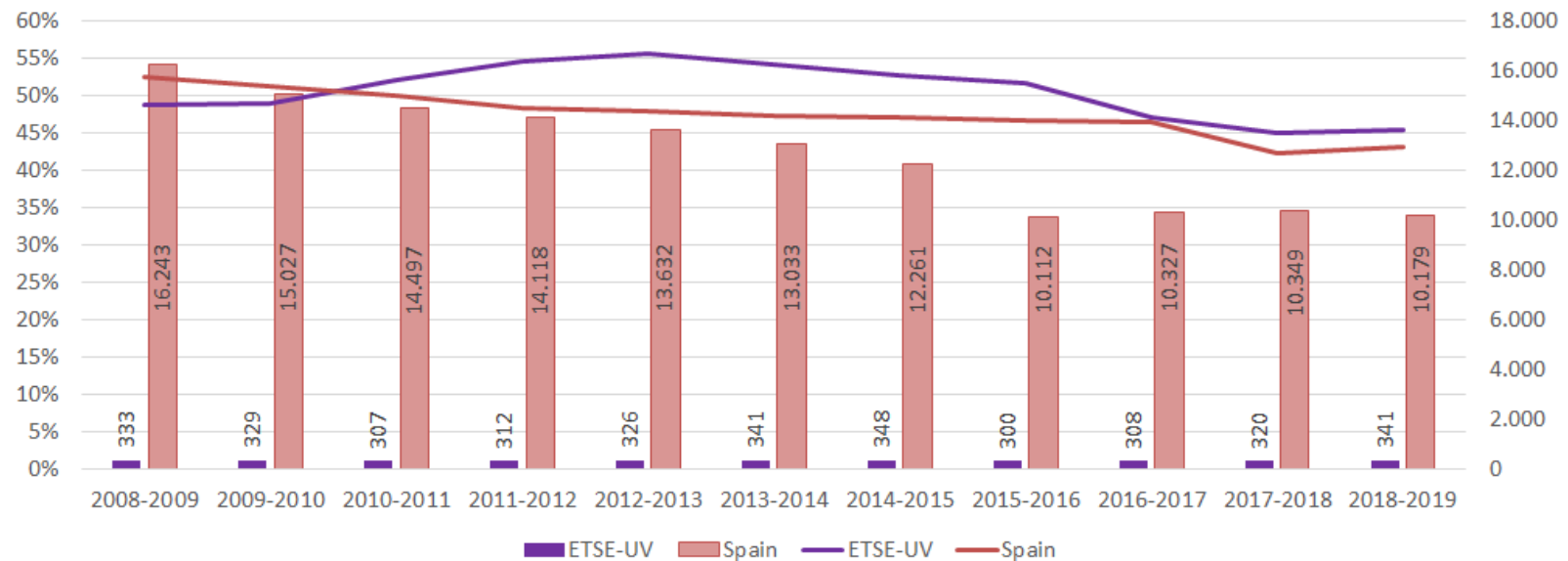

Fig. 3. Percentage of female students at the ETSE-UV vs. total number of students (undergraduate). Spain's situation is used as a benchmark. Field '071101 - Industrial Chemical Engineering'.

pre-period between 2008-2009/2012-2013 and a post-period between 2013-2014/2018-2019. This division allows to mitigate the effects of the transient from Pre-Bologna to Bologna-compliant degrees. The model includes the field of study (see Table I), to control for structural differences, as well as its interaction with the program. This interaction term would control for a possible different impact of the program in the different fields. Fig. 4 shows that there has been a significant effect of all the elements (gender, program, fields) of the model. In particular, the proportion of female students at the ETSE-UV has increased in the post period for the aggregation '06 - Informatics' and '071401 - Computer Engineering', as well as for the field '071405-Electronic Engineering', but, surprisingly, it has decreased in the field '071101 - Industrial Chemical Engineering'. The specific results (in a logistic scale) and their significance are shown in Table II.

To understand the magnitude of the effect, we can analyze the change in the ratio women-to-men, what is also known as the Odds Ratio (OR). The OR after the program has increased a 29,3\% for the field '071405-Electronic Engineering', where it changes from 1 woman every 7 men to 1 in (approximately) 5. For the aggregation '06 - Informatics' and '071401 - Computer Engineering' the increase is lower, $17 \%$, but still significant, going from 1 in 6 to 1 in 5. Finally, the field '071101 - Industrial Chemical Engineering' shows a $10 \%$ fall staying in the approximately 1 to 1 ratio.

The results from Fig. 4 and the OR analysis lead us to prove that, the larger the gender gap, the larger the impact of the pilot program as
TABLE II

PARAMETERS OF THE LOGISTIC REGRESSION MODEL. FIELD OF STUDY 071405 IS TAKEN (BY DEFAULT) AS THE BASE-LINE LEVEL

\begin{tabular}{lrrrr}
\hline & Estimate & Std. Error & $\mathrm{z}$ value & $\mathrm{p}$-value \\
\hline (Intercept) & $-1,99$ & 0,05 & $-41,44$ & $<0,05$ \\
post & 0,26 & 0,07 & 3,74 & $<0,05$ \\
Inf.+ Comp. Eng. & 0,25 & 0,08 & 3,35 & $<0,05$ \\
Ind. Chem. Eng. & 2,07 & 0,07 & 29,85 & $<0,05$ \\
post:Inf.+ Comp. Eng. & $-0,10$ & 0,10 & $-0,99$ & 0,32 \\
post : Ind. Chem. Eng. & $-0,36$ & 0,10 & $-3,72$ & $<0,05$ \\
\hline
\end{tabular}

expressed in the research hypothesis H1. However, as stated by our hypothesis $\mathrm{H} 2$, institutions working towards decreasing the gender gap cannot remain confident regarding traditionally gender balanced degrees, as it is the case of Chemical Engineering at the ETSE-UV. The effort towards narrowing this gap needs to be continuous over time and focus on all STEM related degrees.

\section{CONCLUSION}

A continuous effort from educational institutions, public entities, professionals and families is needed in order to break the gender gap in Science, Technology, Engineering and Mathematics (STEM). Series of data show that even traditionally regarded as female-oriented disciplines can experience a leakage of women moving to other 


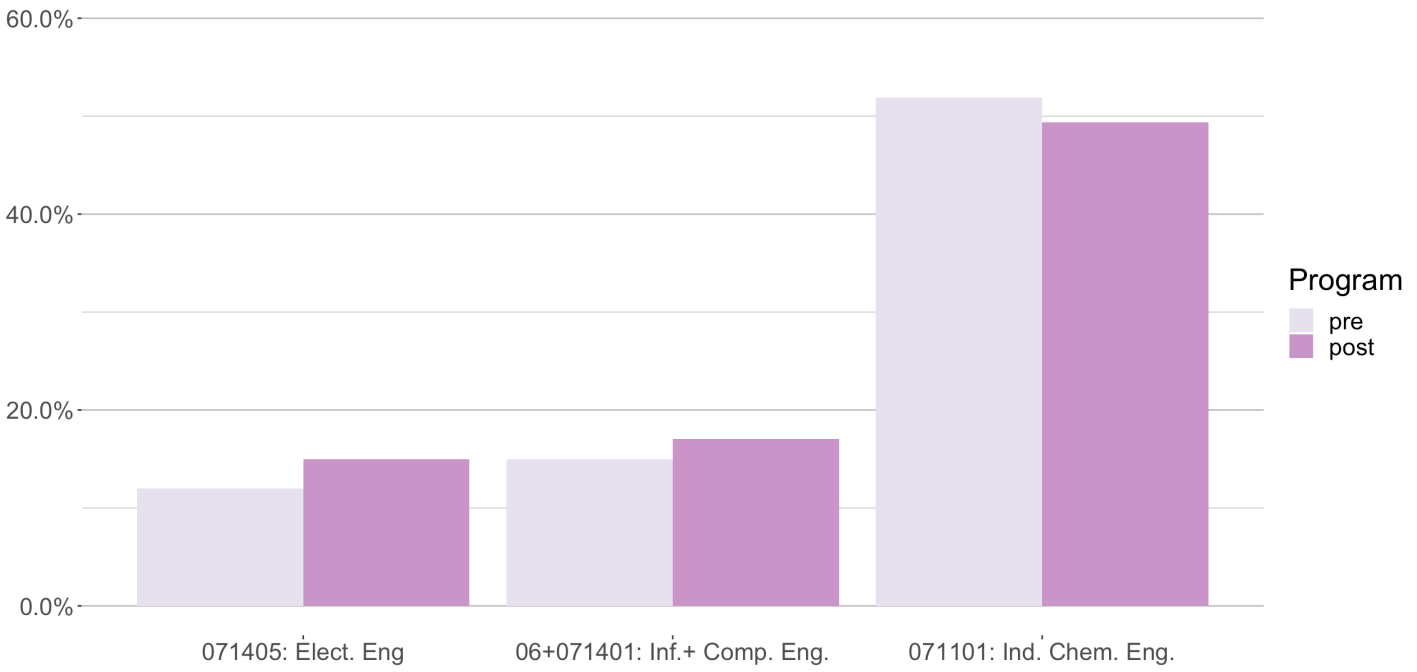

Fig. 4. Pre-post proportion of women in the three fields of study at the ETSE-UV.

areas. In fact, the results presented in this paper show an increase in the proportion of female students after the application of the pilot program in two of the three considered disciplines, specifically in those which traditionally showed a smaller proportion. However, the program did not consider as a specific target Chemical Engineering, and results indicate that this degree is suffering a leakage of female students. The problem is three-fold: engaging girls to access these studies, retaining and motivating them to graduate, and building professional support networks alongside with effective policies to conciliate the personal and professional life. Initiatives such as the ETSE-UV project at a higher education level are seminal to raise awareness towards the gender gap, driving towards a gender-sensitive culture or society.

\section{ACKNOWLEDGEMENT}

This work was partially supported by the project FCT-18-13147 from the Spanish Foundation for Science and Technology (FECYT), the Ministry of Science and Innovation, the Spanish State Research Agency (AEI) and the European Regional Development Fund (ERDF) under project RTI2018-095820-B-I00, the project MTM2016-77501$\mathrm{P}$ from the Spanish Ministry of Economy and Competitiveness and the projects UV-SFPIE-PID19-1097673, UV-SFPIE-PID19-1097874, UV-SFPIE-PID19-1098335 from the Staff Development and Educational Innovation Service (SFPIE) of University of Valencia.

The authors would like to thank Capgemini (https://www. capgemini.com/en), Singularity Experts (https://singularity-experts. $\mathrm{com} /$ ) and all the project's sponsors. The contribution and support of the Vice-Rectorate for Equality, Diversity and Sustainability (University of Valencia); the Equality Unit (University of Valencia); the Scientific Culture and Innovation Unit (University of Valencia); and the Center for Training, Innovation and Educational Resources in the Scientific, Technological and Mathematical fields (CEFIRE STEM, Conselleria of Education, Research, Culture and Sports of the Generalitat Valenciana), are appreciated and acknowledged by the authors. Finally, we would like to thank primary and secondary schools that participate in the program, the STEM experts, as well as all ETSE-UV's staff, in addition to the entities and faculties of the University of Valencia that have supported Girls4STEM.

\section{REFERENCES}

[1] UNESCO. Cracking the code: Girls' and womens' education in Science, Technology, Engineering and Mathematics (STEM). 2017. [Online]. Available: http://unesdoc.unesco.org/images/0025/002534/253479e. pdf (accessed 18th July 2019).
[2] E.A. Cech, M. Blair-Loy, "The changing career trajectories of new parents in STEM," PNAS, vol. 116, no. 10, pp. 4182-4187, 2019.

[3] S. Sassler, J. Glass, Y. Levitte, K.M. Michelmore, "The missing women in STEM? Assessing gender differentials in the factors associated with transition to first jobs," Soc. Sci. Res., vol. 63, pp. 192-208, March 2017.

[4] Isaca.org. (2017). The future techworkforce: breaking the gender barriers. [Online]. Available: http://www.isaca.org/info/ 2017-women-in-technology-survey/index.html (accessed 18th July 2019).

[5] M.E. Heilman, T.G. Okimoto, "Motherhood: A potential source of bias in employment decisions," J. Appl. Pshychol., vol. 93, no. 1, pp. 189-198, 2008.

[6] D. Bilimoria, S. Joy, X. Liang, "Breaking barriers and creating inclusiveness: lessons of organizational transformation to advance women faculty in academic science and engineering," Hum. Resour. Manag., vol. 74, no. 3, pp. 432-441, 2008.

[7] C. Ashcraft, B. McLain, E. Eger, "Women in Tech: The facts," National Center for Women \& Technology (NCWIT). 2016. Available: https:// www.ncwit.org/resources/women-tech-facts-2016-update (accessed 18th June 2019).

[8] L. Lamolla, A.M. González Ramos, "Tick-tock sounds different for women working in IT areas," Community Work Fam., pp. 1-16, 2018.

[9] S. Rueda, C. Botella, E. López-Iñesta, P. Marzal, "Estrategias para aumentar la diversidad de género en la Educación Superior CTIM", Actas de las XXIV Jornadas sobre Enseñanza Universitaria de la Informática, Murcia, España, 2019, vol. 4, pp. 111118. Available: http://www.aenui.net/ojs/index.php?journal=actas_jenui\& page $=$ article\&op=view\&path $\backslash \% 5 \mathrm{~B} \backslash \% 5 \mathrm{D}=528$ (accessed 29th July 2019).

[10] C. Botella, S. Rueda, E. López-Iñesta, P. Marzal, "Gender diversity in STEM disciplines: A multiple factor problem," Entropy, vol. 21, no. 1, 2019.

[11] World Economic Forum, "The future of jobs report 2018," World Economic Forum, Geneva, Switzerland, 2018. Available: http://reports. weforum.org/future-of-jobs-2018/ (accessed 5th July 2019).

[12] EU Skills Panorama, "STEM skills Analytical Highlight," ICF \& Cedefop for the European Commission, 2014. Available: https://skillspanorama.cedefop.europa.eu/sites/default/files/EUSP_AH_ STEM_0.pdf (accessed 5th July 2019).

[13] iClaves \& European Commission. Women in the digital age, 2018. Available: https://ec.europa.eu/digital-single-market/en/news/ increase-gender-gap-digital-sector-study-women-digital-age (accessed 5th July 2019).

[14] C. O'neil. Weapons of Math Destruction: How Big Data Increases Inequality and Threatens Democracy, 1st ed. New York, (USA): Broadway Books, Crown Publishing Group, 2016.

[15] M. West, R. Kraut, H.E. Chew, "I'd blush if I could: closing gender divides in digital skills through education," UNESCO \& EQUALS Skills Coalition, 2019. Available: https://unesdoc.unesco.org/ark:/48223/ pf0000367416 (accessed 5th July 2019). 
[16] Ministerio de Educación y Formación Profesional. Estadísticas e Informes Universitarios. Website. Available: http://www.educacionyfp.gob. es/servicios-al-ciudadano-mecd/estadisticas/educacion/universitaria.html (accessed 18th June 2019).

[17] M. Sáinz, J. Müller, "Gender and family influences on Spanish students' aspirations and values in STEM fields," Int. J. Sci. Edu., vol. 40, pp. 188203, 2018.

[18] N. Olmedo-Torre, F. Sánchez Carracedo, M.N. Salán Ballesteros, D. López Álvarez, A. Pérez-Poch, M. López Beltrán. "Perfil de las ingenieras TIC versus el de otras mujeres STEM," in Actas de las XXIV Jornadas sobre Enseñanza Universitaria de la Informática, Barcelona, España, 2018, vol. 3, pp. 255-262. Available: https://upcommons.upc.edu/ handle/2117/122675 (accessed 18th June 2019).

[19] J. S. Eccles, A. Wigfield, "Motivational beliefs, values and goals," Annual Review of Psychology, vol. 53, pp. 109-132, 2002.

[20] J. S. Eccles, P. Frome, K. Suk Yoon, C. Freedman-Doan, J. Jacobs. "Gender-role socialization in the family: a longitudinal approach," in The developmental Social Psychology of gender, T. Eckes, H. M. Trautner, Eds. New Jersey: Lawrence Erlbaum Associates Publishers, 2000, pp. 333-360.

[21] M. Sáinz. Aspectos psicosociales de las diferencias de género en actitudes hacia las nuevas tecnologías en adolescentes. $\mathrm{PhD}$ Thesis, Universidad Nacional de Educación a Distancia (Spain), 2007.

[22] E.S. Weisgram, R.S. Bigler, "Girls and science careers: The role of altruistic values and attitudes about scientific tasks," J. Appl. Dev. Pshychol., vol. 27, pp. 326-348, 2006.

[23] OECD. The Pursuit of Gender Equality: An Uphill Battle. OECD Publishing: Paris, France, 2017. Available: http://www.oecd.org/ publications/the-pursuit-of-gender-equality-9789264281318-en.htm (accessed 7th June 2019).

[24] A.J. Kersey, E.J. Braham, K.D. Csumitta, M.E. Libertus, J.F. Cantlon, "No intrinsic gender differences in children's earliest numerical abilities," NPJ Sci. Learn., vol. 3, pp. 1-10, 2018.

[25] A. García-Holgado, F.J. García-Peñalvo, F.J. Mena, C. González, "Introducción de la Perspectiva de Género en la docencia de Ingeniería del Software. [Introduction of the Gender Perspective in the Teaching of Software Engineering]," in Actas del IV Congreso Internacional sobre Aprendizaje, Innovación y Competitividad. CINAIC Zaragoza, España, 2017, pp. 627-631. Available: doi:10.26754/CINAIC.2017.000001_134 (accessed 7th July 2019)

[26] L. Schiebinger, I. Klinge, Gendered Innovations: Mainstreaming Sex and Gender Analysis into Basic and Applied Research, 2010. Available: http://www.eif.gov.cy/mlsi/dl/genderequality.nsf/ 0/7CE1FD0F091FAD76C22580F9002FBC4E/\$file/Mainstreaming $\% 20$ sex $\backslash \% 20$ and $\backslash \% 20$ gender $\backslash \% 20$ analysis $\backslash \% 20 \backslash \% 20$ into $\backslash \% 20$ basic $\backslash$ $\% 20$ and $\backslash \% 20$ applied $\backslash \% 20$ research.pdf.

[27] R. Fernández-Cézar, N. Solano-Pinto, "Attitude towards School Science in Primary Education in Spain," REDIE. Rev. Elec. Inv. Educ., vol. 19, no. 4, pp. 112-123, 2017.

[28] R. Fernández-Cézar, N. Solano-Pinto, M. Muñiz-Hernández, “iMejoran los proyectos de divulgación con experimentación la actitud hacia las clases deficiencias? [Do experimentation outreach programs improve the attitudes towards school science?]," Rev. Educ., vol. 381, pp. 285-307, 2018.

[29] P. Barmby, P. Kind, K. Jones, "Examining changing attitudes in secondary school science," Int. J. Sci. Edu., vol. 30, no. 8, pp. 1075-1093, 2008.

[30] J.A. Kitchen, G. Sonnert, P.M. Sadler, "The impact of college-and university-run high school summer programs on students' end of high school STEM career aspirations," Sci. Educ., vol. 102, no. 3, pp. 529$547,2018$.

[31] M.J. Mohr-Schroeder, C. Jackson, M. Miller, B. Walcott, D. L. Little, L. Speler, W. Schooler, D.C. Schroeder, "Developing middle school students' interests in STEM via summer learning experiences: See Blue STEM camp," SSMA, vol. 114, no. 6, pp. 291-301, 2014.

[32] T. Roberts, C. Jackson, M.J. Mohr-Schroeder, S.B. Bush, C. Maiorca, M. Cavalcanti, D.C, Schroeder, A. Delaney, L. Putnam, C. Cremeans, "Students' perceptions of STEM learning after participating in a summer informal learning experience," Int. J. STEM Educ., vol. 5, no. 1, pp. 35, 2018.

[33] C. Demetry, S. Sontgerath, "A middle school engineering outreach program for girls yields STEM undergraduates," in ASEE Annual Conference \& Exposition, 2017.

[34] Fundación Bancaria "la Caixa", FECYT, Everis. (2015). ¿Cómo podemos estimular una mente científica?. [Online]. Available: https://www. fecyt.es/es/publicacion/como-podemos-estimular-una-mente-cientifica.
[35] J. Legewie, T. A. DiPrete, "The high school environment and the gender gap in science and engineering," Sociol. Educ., vol. 87, no. 4, pp. 259280,2014

[36] M.E. Heilman, C.J. Block, J.A. Lucas, "Presumed incompetent? Stigmatization and affirmative action efforts," J. Appl. Psychol., vol. 77, no. 4, pp. 536-544, 1992.

[37] A.B. Diekman, M. Steinberg, E.R. Brown, A.L. Belanger, E.K. Clark, "A goal congruity model of role entry, engagement, and exit: Understanding communal goal processes in STEM gender gaps," Pers. Soc. Pshychol. Rev., vol. 21, no. 2, pp. 142-175, 2017.

[38] A.B. Diekman, E,K, Clark, A.L. Belanger, "Finding common ground: synthesizing divergent theoretical views to promote women's STEM pursuits," Soc. Issues Policy Rev., vol. 13, no. 1, pp. 182-210, 2019.

[39] M. Beard. Women \& Power: A manifesto, 1st ed. London (UK): Profile books, 2017.

[40] L. Howe-Walsh, S. Turnbull, "Barriers to women leaders in academia: tales from science and technologies," Stud. High. Educ., vol. 41, no. 3, pp. 415-428, 2016.

[41] A. García-Holgado, F.J. Mena, F.J. García-Peñalvo, C. González, "Inclusion of gender perspective in Computer Engineering careers: Elaboration of a questionnaire to assess the gender gap in tertiary education," in IEEE Global Engineering Education Conference (EDUCON), Tenerife, España, 2018, pp. 1547-1554. Available:https://repositorio.grial.eu/handle/grial/ 1202 (accessed 5th July 2019).

[42] M. Cobos et al., "Game-based learning supported by audience response tools: game proposals and preliminary assessment," In 4th International Conference on Higher Education Advances (HEAD), Valencia, España, 2018, pp. 605-612. Available: https://riunet.upv.es/handle/10251/109637 (accessed 5th July 2019).

[43] R. Kay, A. Lesage, "A strategic assessment of audience response systems used in higher education," Australasian J. Educ. Tech., vol. 25, pp. 235-249, 2009.

[44] S. Chopra, M. Mirsafian, A. Khan, L. Golab, "Gender differences in science and engineering: a data mining approach," in 22nd International Conference on Extending Database Technology, 22nd International Conference on Database Theory (EDBT/ICDT), March 2019.

[45] J.J. Merelo Gervós, C. Merelo Molina, "Evolución de la Matrícula Femenina en el Grado de Informática en Universidades Públicas Españolas." 2017. Available: https://search.datacite.org/works/10.13140/ RG.2.2.19608.08969 (accessed 4th July 2019). 